\title{
Green purchasing: the effect of parenthood and gender
}

\author{
Matteo Migheli ${ }^{1}$ D
}

Received: 21 May 2019 / Accepted: 28 October 2020 / Published online: 28 November 2020

(c) The Author(s) 2020

\begin{abstract}
The extant literature has inquired the effect of several socio-economic individual characteristics on green purchasing, showing that education, social status and other individual characteristics may enhance virtuous behaviours, but has paid few attention to parenthood and to the presence of children. Theoretical models of microeconomic choices show that if the parents' utility includes that of children, then their presence should affect parents' green purchases. Indeed, parents should desire a sustainable world for their children to have access to enough resources. Using data from 61 countries, this paper inquires whether parenthood and the number of children affect people's decisions about green consumption; in addition the presence of a gender effect (i.e. mothers being more prone to green choices than fathers) exists. The empirical evidence shows that having children decreases the probability of buying green products; an increasing number of children have the same effect. However, parenthood and number of children have opposite effects on fathers and on mothers. Policymakers and marketing divisions of firms may benefit from this empirical evidence. In addition, analyses are performed on homogeneous clusters of countries to account for possible differences due to different environmental engagement or level of economic development. The results show that, while the gender effect is persistent, that of parenting and the number of children is not statistically significant in affluent countries. This last result suggests that budget constraints are a major factor affecting green purchases.
\end{abstract}

Keywords Green purchasing · Parenthood · Number of children $\cdot$ Gender

\section{Introduction}

During the last decades of the twentieth century, people around the world have become more and more concerned about the environment, because of the continuous and accelerating depletion of natural resources (Fransson and Gärling 1999). Over time, consumers have changed their attitudes and started to prefer green products to their brown substitutes. Roberts (1996) highlights that US consumers have started this process of habit change already in the first part of the 1980s, when the US media began to sensitise the population about

Matteo Migheli

matteo.migheli@unito.it

1 Department of Economics and Statistics "Cognetti de Martiis", University of Torino, Lungo Dora Siena, 100, 10153 Torino, Italy 
the environmental problems. According to Schlegelmilch et al. (1996) in the mid-1990s $82 \%$ of the UK citizens already rated environmental problems as urgent, showing a high degree of environmental concern, which translated in a demand for interventions aimed at preserving the environment. In addition, other studies (Suki 2016) highlight that environmental concern also increases the purchases of green goods.

Several studies focus on green consumption ${ }^{1}$ and on the individual characteristics that foster it. Green consumers have been found to be opinion leaders, people who like to try new products (Shrum et al. 1995), highly educated (Paul and Rana 2012) and from affluent households (Chan 2000a; Zhu et al. 2013). Shedding light on individual behaviour, the study of the demand side for green products is relevant not only because understanding who the green consumer is allows designing strategies that foster this virtuous behaviour. Indeed, Cherian and Jacob (2012) show that green demand fosters green production, and Coad et al. (2009) find that individual environmental concern increases the support for environmental policies. In addition, evidence exists, suggesting that women are generally more concerned with the environment and the environmental consequences of their actions than men are (the next section will provide references to the extant literature on the issue).

The extant literature has also unveiled that altruistic people are more likely to be green consumers than non-altruistic (see for example Straughan and Roberts 1999, which constitutes an early study on the issue). This result is not surprising, as the protection of the environment usually entails to bear costs individually for producing positive externalities for the society. However, the economics literature shows also that a particular event in life-parenthood—-tends to increase the altruism of people who experience it. From a theoretical point of view, the utility models with overlapping generations, and other models, which include the offspring's utility in that of parents, predict that, if some event today will decrease the utility of the children tomorrow, then the parents will try to prevent that event from happening or will try to limit its consequences. Empirically, Ziegelmeyer and Zigelmeyer (2016) show that parents are more conservative when they have to choose for their children than when they have to choose for themselves. What the literature suggests, then, is that parents should care for the environment more than non-parents and that the environmental concern might be an increasing function of the number of children a person has. Indeed, as this number grows, so should the penalty in terms of parent's utility engendered by the deterioration of the environmental living conditions for the future adults. Consistently, Migheli (2018) shows that parents are more willing than non-parents to pay voluntary contributions or taxes aimed at financially supporting environmental actions.

Although the literature on individual characteristics of green consumers has inquired several aspects, the effect of parenthood and of the number of children on green purchasing has poorly been studied. The analysis presented in this work aims at providing some evidence in favour of the hypothesis that parents are more likely to be green consumers than non-parents and that this behaviour strengthens as the number of children increases.

\section{Green consumption: a survey of the empirical literature.}

Having children and their number should enter the list of the individual characteristics that shape consumption decisions for the theoretical reasons mentioned in the previous section. However, as the reader will see below, the extant literature has paid very little attention

\footnotetext{
${ }^{1}$ For a comprehensive presentation and discussion of this concept, please refer to Peattie (2010).
} 
to this issue. The most salient results of the works presented in this section highlight that income, education and social norms are strong predictors of one's intentions to purchase green goods.

Deciding which type of product buying requires to be informed both about the environmental situation and the benefits that responsible consumption brings to its preservation and about which products are green (Shen and Saijo 2009). For this reason, highly educated people are more likely to choose green goods (Chan 2000a). Indeed Chan (2000b) reports the results of a study on Chinese consumers and shows that people with low ecological awareness have low ecological affect and are much less likely to purchase green products than consumers more informed about the environmental problems are. Diamantopoulos et al. (2003) and Gan et al. (2008) find similar results for the UK and New Zealand, respectively. Education acts also as a mediator between the desire of healthy lifestyles and the consumption of green products (Hughner et al. 2007; Paul and Rana 2012). Income is another relevant determinant of green purchases. Indeed, eco-friendly goods are often more expensive than their brown substitutes; consequently, people tend to be less prone to buy them, or, given their budget constraints, they purchase less than they wish (Ali et al. 2011; Zhu et al. 2013; Zhao et al. 2014). However, Fleith de Medeiros et al. (2016) and Shao and Ünal (2019) show that consumers who intend to purchase green goods are willing to pay them more than their non-green substitutes.

The economics literature provides evidence for the existence of differences in preferences between men and women in risk-regarding and social preferences (see Croson and Gneezy 2009 for a review), as well as in preferences for governmental protections in the economy (Migheli 2014). Consistently with it, some works showing that women have higher levels of environmental concern than men (Xiao and McCright 2015), Diamantopoulos et al. (2003) and Chekima et al. (2016) found women to purchase more green products than men. However, this evidence is not conclusive: Gilg et al. (2005) found no gender effect in the UK; Chen and Chai (2010) did not detect any effect of this type in Malaysia and the same holds for Zhu et al. (2013) for China. Mostafa (2007) found an even opposite effect, with Egyptian men more concerned about the environment and more prone to purchase green products than women.

Straughan and Roberts (1999) show that, in the USA, altruism is a stronger explanatory variable for green purchasing than environmental concern is. Consistently, also Mazar and Zhing (2010) run three experiments and find altruistic people to buy more green products than less altruistic individuals. Other works point out that individual social norms (that include altruism and collectivism) are strongly related to green behaviour. In particular, Jansson et al. (2010) show that personal norms are determinant in the adoption of eco-innovations; moreover, the consciousness that own decisions affect the future of the environment also contributes to enhance green consumption (Kaufmann et al. 2012). In addition to this evidence about individual values, Suki (2016) highlights that also social norms and the individual desire to adhere to them fosters green purchasing. Liobikiene et al. (2016) show the relevance of both subjective and social norms in determining green consumption in the countries of the EU. This last study is very relevant, as, among those surveyed in this paper, is the only work that analyses more than one country at a time. Two other very recent studies (Liobikienè et al. 2017; Yadav and Patak 2017), respectively, for Austria and Lithuania and for India, have shown that personal norms, social norms and social control on individuals has a positive effect on green purchasing.

A consequence of the previous evidence may be that households with children are more prone to green consumption for at least two reasons. The first is that parents are likely to care for their offspring's future wellbeing, which entails also the preservation of the 
environment. The second reason is that family is an institution, where both altruism and collectivism play a crucial role. Therefore, as these two attitudes towards social life are positively related to green purchasing, it is possible that people with children are more ecofriendly and purchase more green products than people without children. Unfortunately, the literature on this matter is almost inexistent: very few (and relatively old) articles have marginally addressed the issue. Considering gender and children together, Laroche et al. (2001) analyse a sample of Canadians and shows that women with at least one child have a higher willingness to pay for green goods than men or childless women. However, the evidence about the link between parenthood and green purchasing is not univocal: Diamantopoulos et al. (2003) did not find any relationship between the number of children and the green behaviour of a sample of UK citizens; they also find weak evidence that married individuals are heavier green consumers than singles.

Before continuing with the presentation of the data and the methodology used in the empirical analysis, it may be useful to summarise some of the works that contain policy recommendations. The surveyed literature and some other works suggest that the primary channel to promote green consumption is marketing. Examining the wine market, Barber et al. (2009) proposes to use a selective marketing approach to increase the purchases of green goods. Rahbar and Wahid (2011), Nittala (2014) and Goh and Balaji (2016), analysing different countries (one for each of the cited articles), have found a positive effect of advertising and trust in eco-labels on purchases; Vazifehdoust et al. (2013) reach analogous conclusions, studying the behaviour of Iranians.

\section{Data and methodology}

The data used in the analysis are from two datasets. The first is the World Values Survey (WVS), a large dataset provided by the WVS Association, "a global network of social scientists studying changing values and their impact on social and political life, led by an international team of scholars, with the WVS Association and WVSA Secretariat headquartered in Vienna, Austria." 2 The questionnaire is the same for all the countries surveyed. In each of them an institution specialised in data collection and treatment-usually a university - is in charge of questionnaire administration and data collection. From this dataset the dataset used in this paper takes the variable about green purchasing and the socioeconomic characteristics of the interviewee and of her household are taken. In particular, the education, gender, age, marital status, employment status and number of children of the respondent are used as regressors. The variable used as dependent in the regressions is dichotomous and takes value 1 if the responder reported that she had bought "products that [she] think[s] are better for the environment" in the last 12 months; the answer is coded 0 otherwise. In particular, the fourth wave (ending in 2004) of the WVS is used in the analysis. There are two main reasons for this choice: the first is that from the previous waves the question about green purchasing was absent. The second is that the subsequent waves (fifth and sixth) recorded responses after the beginning of the international economic crisis that has affected countries and areas within each country differently (Capello et al. 2015).

The second set of data includes several economic and environmental variables at country level, taken from the World Bank Open Data repository. This information is not

\footnotetext{
${ }^{2}$ From the WVS website: https://www.worldvaluessurvey.org/WVSContents.jsp.
} 
available in the WVS, which is a rich dataset, however limited to the individual dimension, with no information about the countries included. Indeed, the analysis uses data from 61 countries $^{3}$ around the world; therefore it should include at least a dummy variable for each country included, but one, to account for country fixed effects. However, instead of using a battery of 60 dummies, the analysis uses a set of variables measured at country level, which capture some characteristics that may influence the ecological behaviour of the citizens. This procedure, together with clustering the standard errors at country level, allows for cleaning the results at individual level from as much noise as possible coming from country fixed effects. These last, in particular, may include environmental policies, the availability of funds to pursue them, the level of economic development of the country. The level of economic development is captured by the very traditional measure of per capita GDP, which is generally positively linked with environmental concern (Halbheer et al. 2006). Other characteristics that may have some impact on the environment are also included; among them is the population density, which increases the consumption of natural resources (Thalmann 2004) and affects the people's support to environmental policies (Halbheer et al. 2006; Nelson et al. 2007). Also the share of population living in urban areas is considered as a relevant control (Cárdenas Rodríguez et al. 2016). The included measure of environmental degradation is the value of $\mathrm{CO}_{2}$ emissions per capita. "Appendix A" reports the list of all the countries included in the analysis. However, as these controls may hide some important country-specific characteristics, further estimates are provided, which divide the countries in three homogeneous clusters, and use fixed effects at country levels (details on this are presented in "Appendix B").

Two techniques are used to analyse the data: regressions based on probit and Heckman selection models. Technical details about these methods are provided in the second "Appendix B" of this paper. This section will present the main aspects of how estimations are implemented and the results obtained. For the sake of clarity, it is worthy to recall that probit regressions are based on maximum likelihood estimation (MLE), while Heckman selection models (HSM) combine a first stage that uses MLE to clean the selected sample from the possible selection bias, and a second stage, where the effect of the variable of interest on the outcome is estimated through ordinary least squares (OLS).

The main results obtained from MLE report the effect of having children vs. non-having offspring and the effect of the number of children for the subsample of respondents who are parents on green purchasing. In other words, first the effect of a dummy capturing whether the respondent has children $($ dummy $=1)$ or not $($ dummy $=0)$ on whether the household has purchased green products during the last 12 months is estimated. Then another equation, where only parents are included, inquires the effect of the number of children on the decision of purchasing green. The idea behind these two different estimation is the following: on the one hand having children is expected to induce greener behaviours than being childless. On the other hand, as the number of children increases, the behaviour of the individual/household should to become "greener," as the environmental concern should be positively related to the number of children. In both cases, some different specifications are estimated for the sake of providing the reader with robustness checks.

The analyses are conducted in the following order: first probit regressions to study the effect of having vs. non-having children on green purchasing, then the effect of

\footnotetext{
3 The WVS includes more than 61 countries; however the information necessary for the analysis presented in the paper is available only for 61 of them.
} 
Table 1 Descriptive statistics of the variables used in the econometric analyses

\begin{tabular}{lcc}
\hline & Mean & Standard deviation \\
\hline Purchased green goods in the last 12 months (\%) & 47.74 & 49.94 \\
Male & 48.45 & 49.98 \\
Has children & 73.04 & 44.37 \\
Children & 1.97 & 1.82 \\
GDP per capita (USD 2002) & 7300.59 & $10,110.31$ \\
Population density (log) & 4.208 & 1.268 \\
CO $_{2}$ emissions (tons per capita) in 1998 & 5.27 & 4.76 \\
Protected areas (log km ${ }^{2}$ ) in 2002 & 8.91 & 8.48 \\
Urbanisation (\% of people living in urban areas) & 62.97 & 19.75 \\
Economic growth in 2002 (\% values) & 1.09 & 1.10 \\
Consumption of electricity (Kwh per capita) in 2002 & 3.828 & 4.316 \\
Age & 40.31 & 15.91 \\
Part-time employees (\%) & 7.50 & 26.33 \\
Self-employed (\%) & 10.94 & 31.22 \\
Unemployed (\%) & 9.42 & 29.21 \\
Retired (\%) & 11.45 & 31.84 \\
Married (\%) & 58.34 & 49.30 \\
Widows (\%) & 5.89 & 23.53 \\
Divorced (\%) & 3.09 & 17.30 \\
Secondary education (\%) & 44.49 & 37.69 \\
Tertiary education (\%) & 14.34 & 35.04 \\
Generalised trust (average on 0-1 scale) & 0.268 & 0.443 \\
Size of town (average on 9 size classes) & 5.049 & 2.524 \\
\hline
\end{tabular}

the number of children on the same variables of interest. In this second case, the first results are obtained through HSM, while the second through MLE. The main variables of interest in all the three cases (HSM and the two MLE) are whether the interviewee has children or not, and their number for the subsample of parents. However, as the extant literature has widely inquired the existence of some gender effect, without finding conclusive evidence, and as men and women may react differently to parenthood (see for instance Thompson and Walker 1989; Schober and Scott 2012) also gender (dummy: male $=1$; female $=0$ ) is a focal variable in the analysis. It is introduced in the regressions both alone and interacted with the dummy for having children or not and with the variable that measures the number of children of the interviewee. The most complete specification includes a large number of controls, which are important to obtain clean estimates for the variables of interest, but do not constitute the focus of the paper. For this reason, the tables included in the main text of the paper present only the coefficients and (where necessary) the marginal effects of the variables of interest. ${ }^{4}$

Table 1 presents the descriptive statistics for the variables used in the analysis. From this table it is also possible to see all the controls that are included in the different specifications

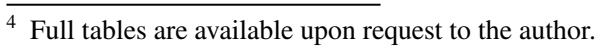


estimated. As it may be noticed, the country-specific controls are measured before 2006, to avoid problems that may have arisen from contemporaneity. The most of these variables are hardly subject to relevant variations from a year to another, so that their value in 2002 may be considered representative as that in 2006. The abovementioned clustering allows also for highlighting differences in the prevalence of green purchasing between clusters: the share of respondents who declared to have purchased green goods is equal to $37.74 \%$ in cluster 1, 40.59\% in cluster 2 and $69.94 \%$ in cluster 3. All the differences between these figures are statistically and significantly different from 0 at $1 \%$ level.

\section{Results}

Table 2 reports the probit estimates that show the impact of having children on green purchasing. The columns of the table show different specification, including different controls. The first five columns are estimated for the full sample (172,848 individuals), while the last three columns report the estimates for the same specification as that in column 5 , but for different age groups. In particular, in the regression presented in column 6 individuals aged between 20 and 44 included are considered; column 7 includes the interviewees aged between 46 and 65 and, finally, the last column of the table is for the subsample of the over-65. According to the figures in the table, having children reduces the probability of purchasing green goods; the effect has the same sign even in the specification where it is not statistically significant. This lack of significance may be due to the lack of enough controls; in other words, the estimates in columns (1) and (2) are noised by the crossed effects between the controls that are not included and the regressors used.

The results are in contrast with the expectations discussed in the first two sections of the paper. However, among others Delle Fave and Massimini (2004) show that parenthood decreases the parents' time available for daily activities including gathering information and purchasing goods; therefore this result is consistent with this change in time use. Moreover, Craig and Baxter (2016) show that this reduction in time available for daily duties other than childcare affects both men and women. In line with other studies, men are on average less prone to purchase green products than women are. Of course, there may be countries (such as Egypt), where the opposite holds (Mostafa 2007), but the negative effect of being male on the variable of interest is largely prevalent in the countries analysed.

The most interesting result of Table 2 is perhaps the sign of the interaction between gender (male) and having children. The coefficients and the marginal effects are almost always positive and statistically significant. This suggests that parenthood increases the probability that men purchase green goods. The total net effect for fathers is still negative in all the columns, indicating that women are anyway more willing to buy ecofriendly products than men are. However, having children affects fathers' behaviour virtuously, while this does not happen for women. In other words, men's environmental concern seems to be positively affected by parenthood. This result is consistent with the models that include the offspring's utility in that of the parents and is very robust to the inclusion of several controls.

Another interesting result is offered by the figures presented in the last three columns of the table. In the last, no effect of gender or of having children is detected. There are two main possible explanations for this outcome. The first is that the sample size is too small for any coefficient to be significant. While there are almost 16,000 interviewees included, they are distributed across 61 countries. However, one may also deem that such a number 


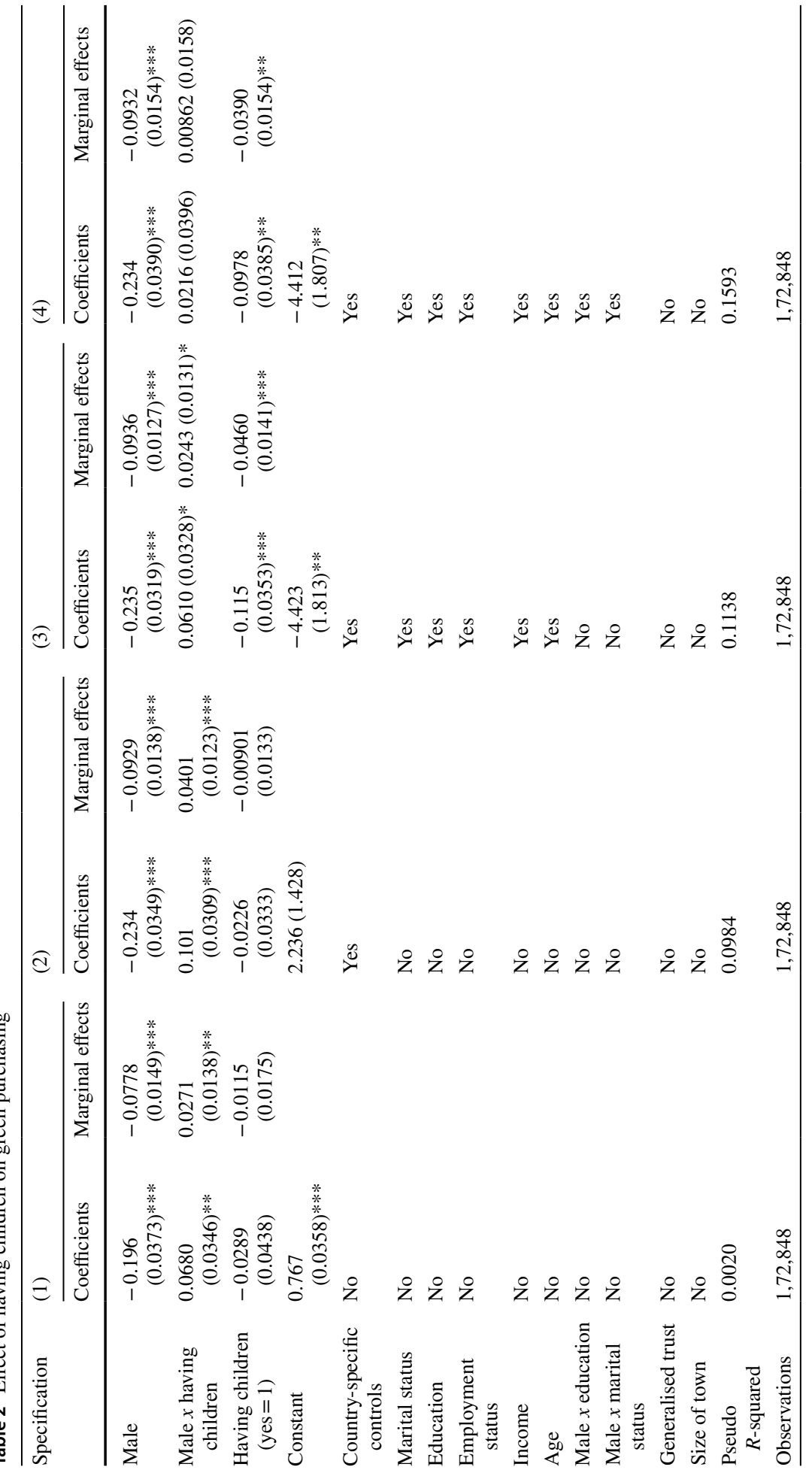




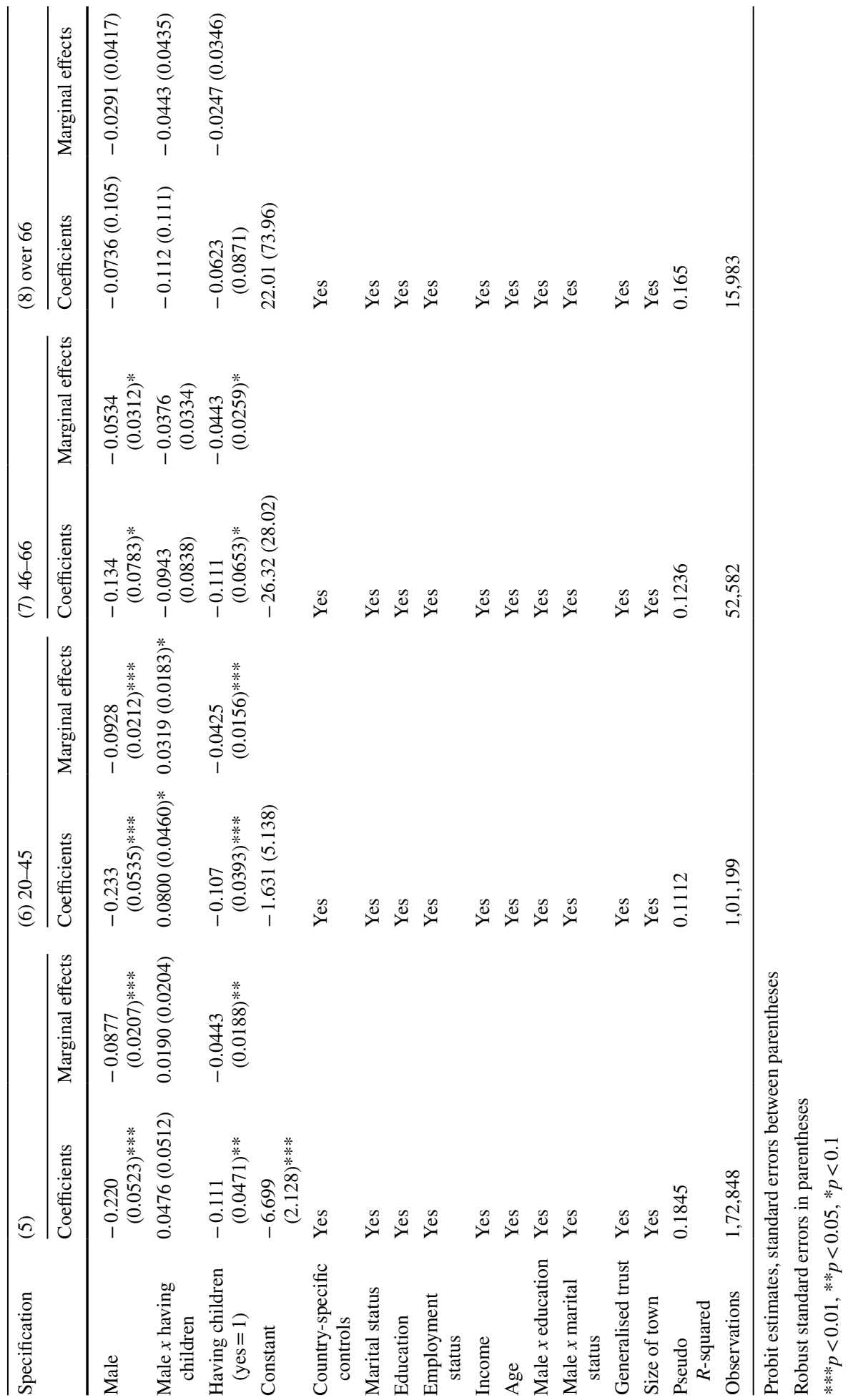


of observations are anyway sufficient to reveal statistical significance, if any. In this second case (which is that preferred by the author of the analysis), the figures suggest that the effect of parenthood is transient and tends to disappear with age, and so does the effect of gender. It seems that as people approach the last days of their life, their preferences become more homogeneous between sexes and parenthood has no longer effect on green purchasing. This may be explained by the fact that parents are particularly concerned about their offspring's life, when children are young and parents bear heavy responsibilities towards them. A second possible interpretation, consistent with the theoretical models that include offspring's utility in that of parents, is the following. People aged 65 or more have children who are older than those of younger individuals. Consequently, the first have a residual life expectation, which is shorter than that the second. Indeed, the older a person is, the less relevant environmental damages are for her utility. Even assuming that all the interviewees are representable through a utility function that includes that of their children, old parents know that the degradation of the environment will have small impact on the lives of their children. The same is not true for young people and persons become parents at young ages: on their lives the progressive deterioration of the environment will have a heavy impact. All this implies that we should observe more environmental concern (and therefore a higher probability of buying green products) in the young than in the old cohorts.

Table 3 presents the estimates obtained using HSM. Here, the selection variable in the first step is having children, while the dependent variable of the second step is, as in Table 2, whether the family of the respondent has purchased green goods in the last 12 months. The figures show that as the number of children increases, the probability of purchasing green products decreases. Consistently with the results presented in the previous table, the interaction term between "Male" and "Number of children" has a positive effect and the coefficient is statistically significant in all the specifications. Finally, the usual gender effect holds. These results, together with those presented before, suggest that not only parenthood has a negative impact on green purchases, but also that these last are a decreasing function of the number of children. In other words, the data show the opposite of what we expected at the beginning of this analysis.

As anticipated, Table 4 proposes estimations that are similar to those presented in Table 3. The difference between the two tables is that the figures in Table 3 are estimated using HSM on the whole sample, while those in Table 4 report MLE (namely probit) for the subsample of parents only (i.e. childless interviewees were dropped before running the regressions). The specifications estimated are the same as those presented in Table 2. The outcome does not differ from that of Table 3: males are generally less prone to purchase green goods than females are, the number of children per se negatively affects the probability of buying green products, but the coefficient of the interaction between "Male" and "Number of children" is again positive and statistically significant. Consistently with what observed in Table 2, the mentioned effects are not statistically significant for the subsample of interviewees aged 65 or more. The same caveats and the same comments exposed commenting the results in Table 2 hold also in this case.

Table 5 presents the results for probit analyses that mirror those presented in Table 2, but the estimations are run at cluster level and country fixed effects are used, instead of the country-specific variables. The table presents the figures for the full model (the fourth specification in Table $2^{5}$ ) and for each of the three clusters. These results are interesting, as

\footnotetext{
5 To save space only the results for the full specification are presented. Those for the other specifications (the same as Table 2) are available upon request to the author.
} 


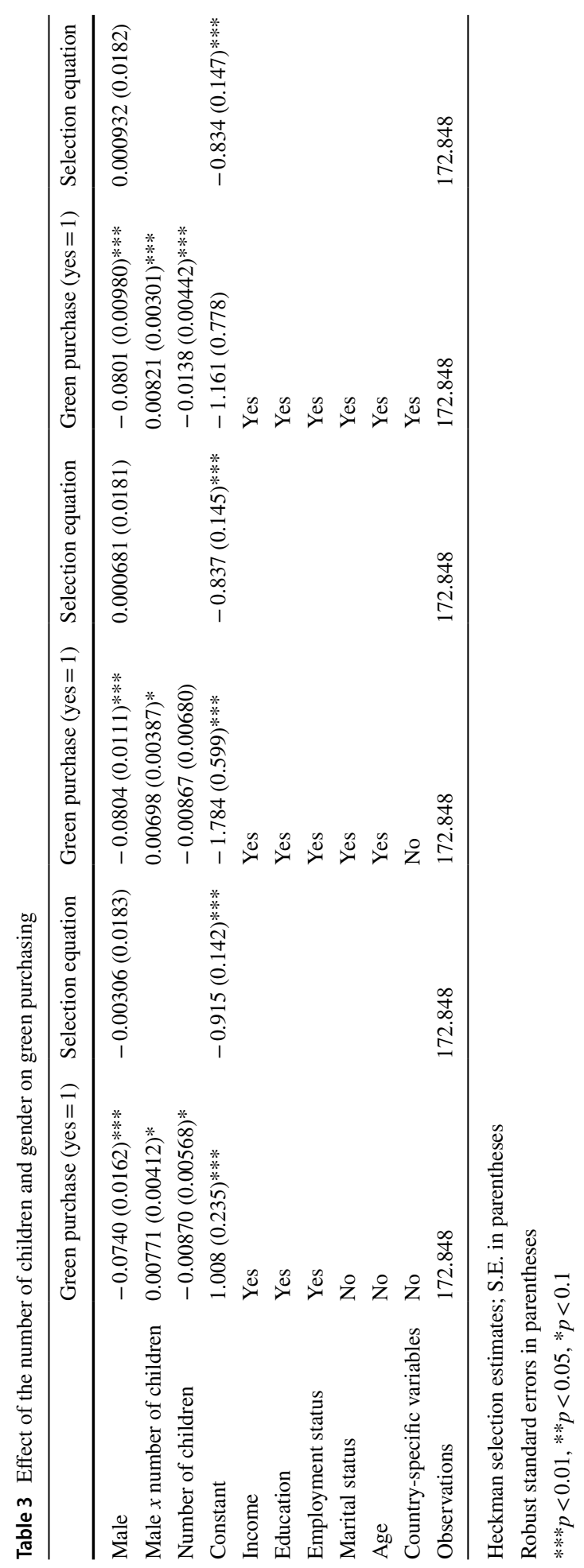




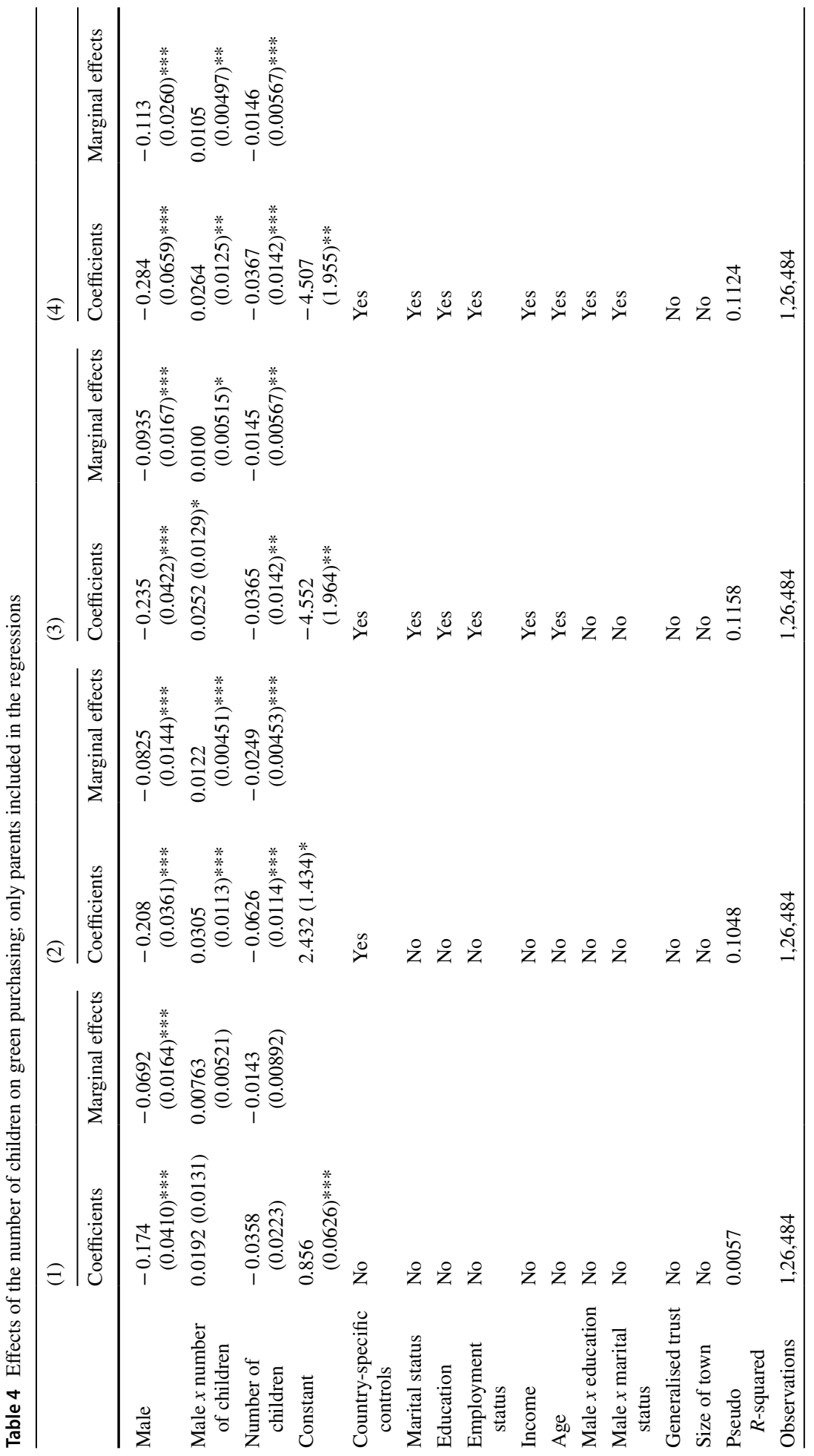




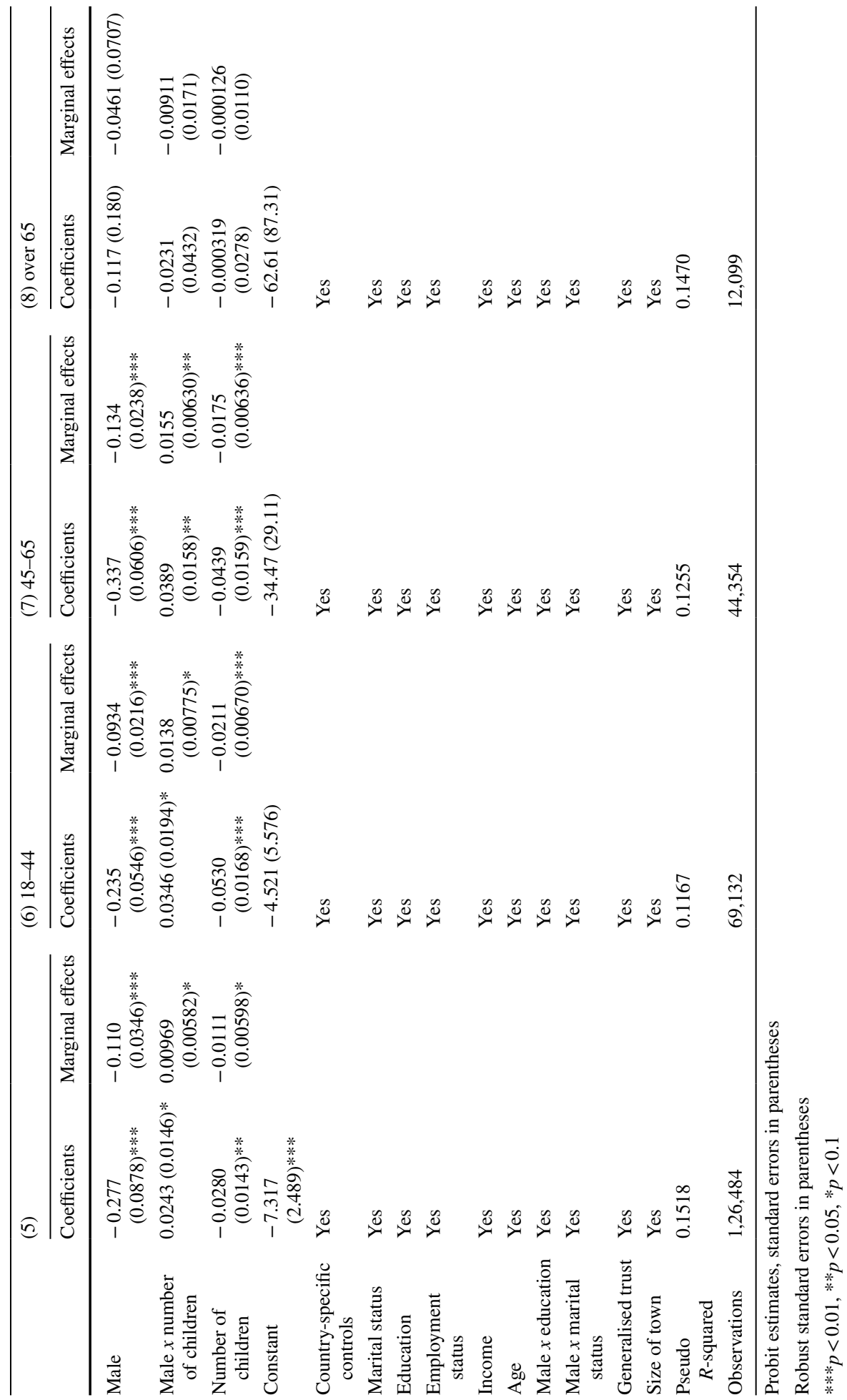




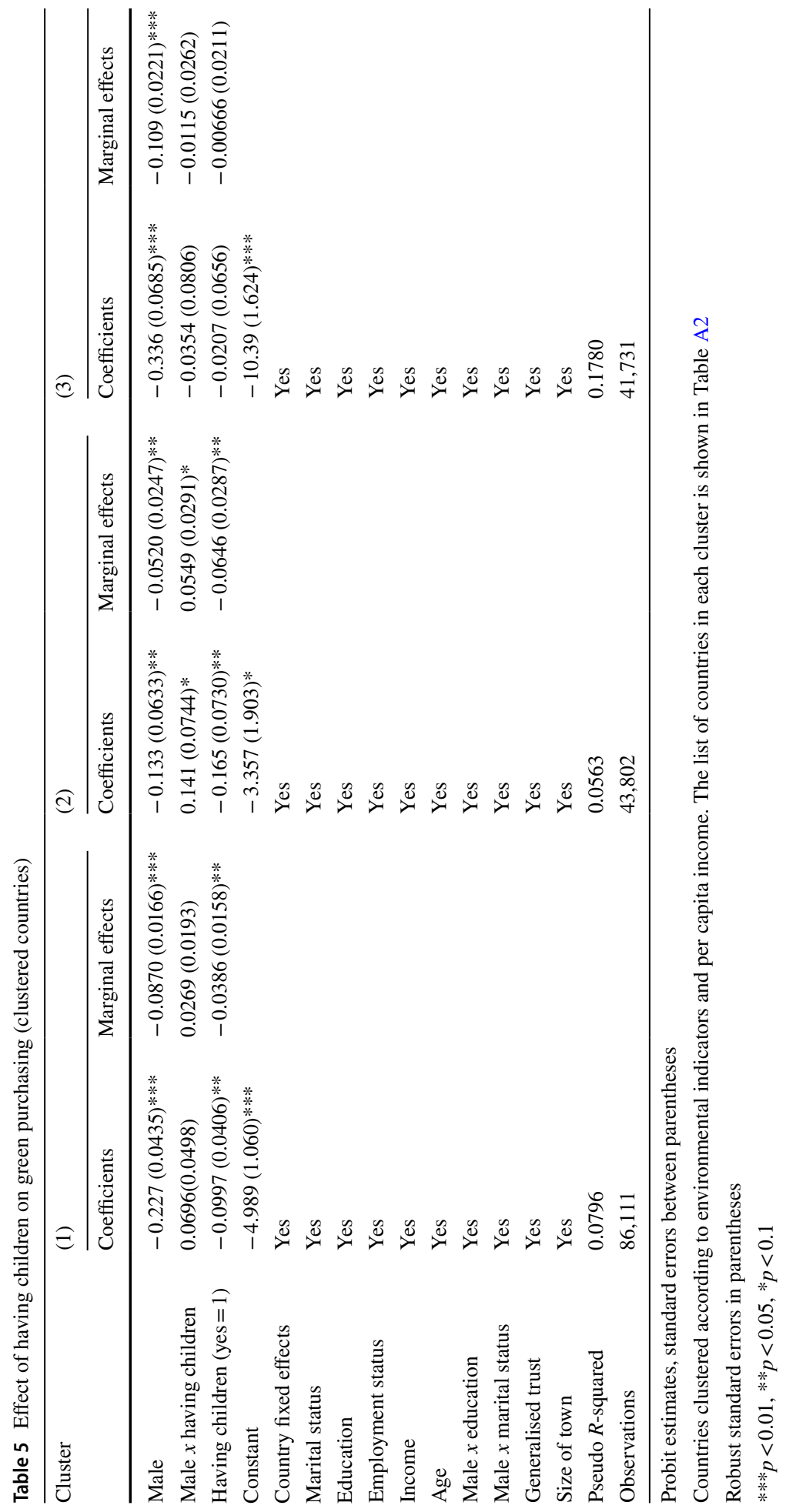




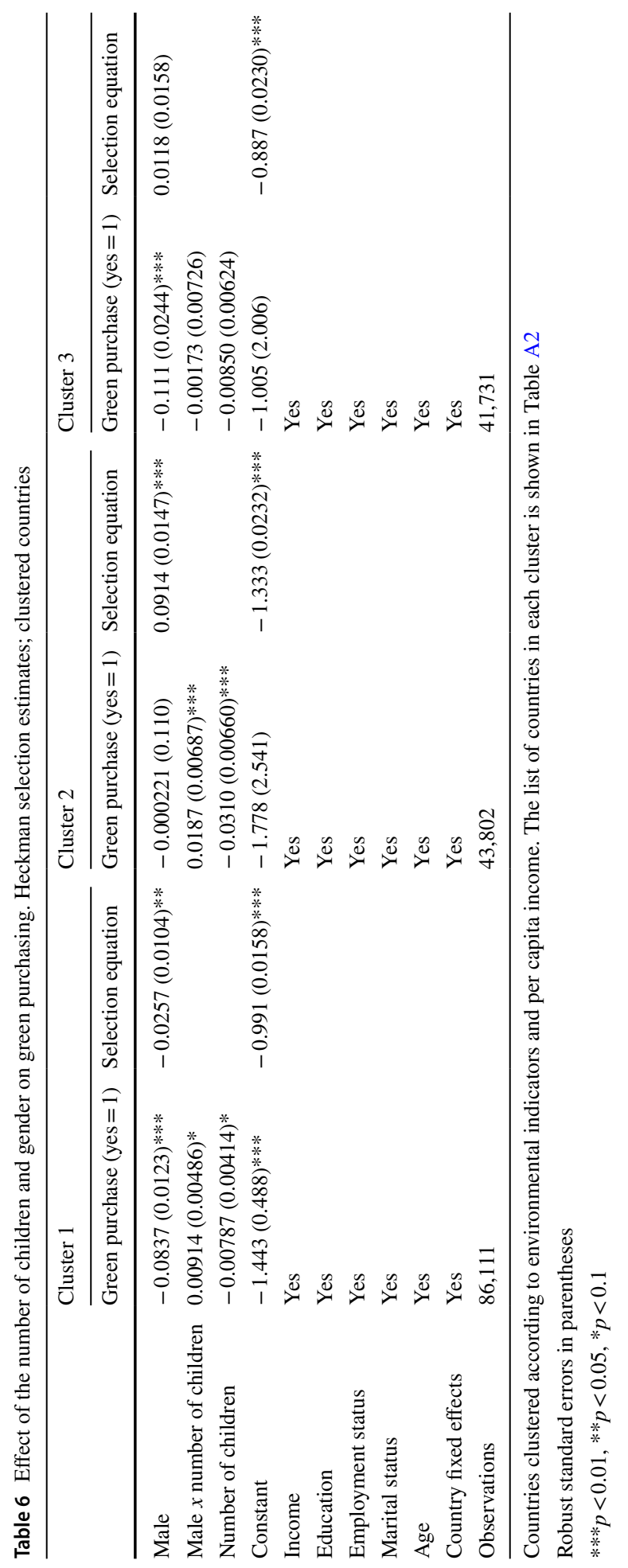


they suggest some important reflections on those presented in the previous tables. First, the effect of being male is persistently negative and statistically significant in all the clusters, indicating that males are in general less concerned with the environment than women. The effect of having children is statistically significant only in the first two clusters of countries, i.e. for levels of income lower than those of countries in the third cluster. This result reinforces the previous interpretation: having children makes budget constraints more stringent, and this appears to be particularly true in lower income countries, where, furthermore, fertility is generally higher than in high-income countries. Table 6 (that shows the effect of the number of children in the sub-samples of parents only) presents analogous effects further supporting the previous interpretation: in middle-income countries, where couples have more children. Indeed the average number of children per couple of parents in cluster 1 is 2.56, while it is 3.14 in cluster 1 (difference statistically and significantly different from 0 at $1 \%$ level); the average number of children for the sub-sample of parents only in cluster 3 is instead equal to 2.42 (again the difference between this values and those of the other two clusters is statistically different from 0 at $1 \%$ significance level). The mitigating effect of children on fathers is visible in clusters 1 and 2 , while it is not statistically significant in cluster 3. Again, where income is higher and therefore households may be less constrained by the additional expenses of parenthood, the only effect that emerges is that of the gender. The figures in Tables 5 and 6 suggest also that the effects detected in the pooled sample are driven by what happens in the countries included in the first two clusters.

\section{Discussion}

The results presented in the previous section contribute to the existing literature as they show regularities in some effects across countries and within homogeneous clusters of countries. As Sect. 2 highlights, the extant empirical literature on green purchasing reveals differences between countries. The results of the present paper suggest that such dissimilarities may be due to different levels of per capita income and environmental concern at macro level. In particular, the negative effect of having children seems to be particular relevant in lower income countries, where budget constraints due to parenthood are more relevant. Such a conclusion is plausible, as the regressions control for household income rescaled according to the specificity of each country. Therefore, the difference between clusters 1 and 3 (both with high environmental footprint, but different levels of economic development, and with similar fertility rates) seem rather due to more stringent budget constraints in cluster 1 than in cluster 2 . Such an evidence is positive, because it suggests that, as per capita income increases (and fertility rates decrease), parenthood does no long discourage households from purchasing green goods. It is necessary to stress here that the coefficients for "having children" and "number of children" variables refer to women, being the effect of gender (male) and children on fathers been captured by the other two variables of interest.

Parents do not seem to pursue green household policies when compared with non-parents; and the same holds for individual with many children when confronted with people with few children. What seems plausible is that the lack of time generated by the presence of (many) children reduces both the time available to gathering information, which is positively linked to green habits, and that available to select products with the aim of purchasing the green. 
An additional possible explanation, which is supported also by the results presented in Table 3 and by those not shown here, but present in the full regressions estimated, is that parents lack money to purchase green products. Indeed, income is positively related to the probability of buying eco-friendly goods, and the literature is explicit in pointing out that these products are in general more expensive than their brown equivalents. The same literature shows also that, on average, consumers may be willing to pay more for a green good than for its brown substitute. However, it is very likely that having children increases the burdens on the household budget, and that these pressures grow with the number of children a couple has. This interpretation is consistent also with the age profile of the phenomenon: parents aged more than 64 usually no longer provide their children with money or consumables. Therefore, for them having children does not affect their decisions about which type of products buying.

What is interesting is also the fact that the figures shown in Table 3 reveal not only a clear distinction between parents and non-parents, but also between families with few and many children. In other words, the effect of parenthood is not dichotomous, but appears to be rather continuous. A last remark is about the net effect of gender: in all the tables, the effect of being male (with or without children) on green purchasing is always negative, and the distance increases with the number of children, as the coefficient (HSM) and the marginal effect (MLE) of the interacted term is always smaller in absolute value than the coefficient of the number of children. In other words, while both this last variable and parenthood induce men to increase their green purchases, none of them is strong enough to overcompensate the negative effect of gender.

From a methodological point of view, the fact that MLE and HSM produce results that are qualitatively similar supports the robustness of the estimates presented in the analysis, in spite of the weaknesses highlighted in the third section of the paper. The effects estimated through HSM are smaller than those obtained by MLE, but the differences are minor. This outcome suggests that the bias introduced by neglecting the selection factors is small and that, therefore, also the estimates in Table 4 are reliable. In addition, also from a methodological point of view, the regressions presented in Tables 5 and 6 show that the inclusion of country fixed effects does not change qualitatively the results presented in the previous tables, suggesting that the differences between income and environmental variables are enough to capture the country-specific effects that affect the decision whether to purchase green goods.

\section{Conclusions}

The analysis presented in this paper contributes to the extant literature on green consumption in some ways. The first is by addressing a research question (whether parenthood and children affect green purchasing) that has so far received poor attention in the literature, but whose answer may have relevant policy implications both at country wide and at firm level. The second is by presenting an analysis based on 61 countries around the world, which allows for a high degree of external validity, so far not reached by the extant studies, which are almost all based on data from one country only at a time. The results of the analysis are indeed statistically robust and indicate the presence of room for policy interventions.

A relevant issue is whether men and women are equally involved in purchasing decisions within households. Indeed, the detected gender differences may depend also on such a division of tasks. Dholakia et al. (1995) and Kuruvilla et al. (2009) show that, while 
women are much more involved in grocery shopping than men, both genders are equally involved in purchasing other goods, such as clothes. Voicu et al. (2009) show that gender equality in chores depends on the level of available technologies (i.e. household appliances) and the level of cultural liberalism, with both positive related to equality in chore division between men and women. However, gender differences may vary for other reasons: Blom et al. (2017) highlight that non-working members of couples do more chores than working members; however such a difference is less prominent in advanced economies, where, furthermore, women are more likely to work outside home. The clustering strategy followed in this paper (Tables 5 and 6) groups countries in clusters that mirror their levels of economic development, which is one of the main drivers of gender differences in chores. The gender effect is strongly persistent in all the clusters, suggesting that duty division within the household does not affect the results much. However, further research should empirically address this specific research question, to unveil possible effects of gender asymmetries in chores as drivers of different green purchasing attitudes.

From a policy perspective, the results of this paper suggest that in particular people who became parents at young age should be incentivised to buy green products, if the intention of policy makers is to increase the consumption of green goods. While the data used in the analysis do not allow for testing whether parenthood reduces green consumption because of lack of time to spend on information and selection of products or because the green products cost more than the brown, actions to incentivise parents to purchase ecofriendly products are needed. In particular the aspect of budget constraints seems to need considering by the policymakers. There are different options on the table: subsidies to parents, proportioned to the number of children, subsidies to the producers of green goods in exchange of lower prices, VAT cuts on green products, etc., although the literature has shown that consumers who are environmentally concerned are also willing to pay more for green goods (Fleith de Medeiros et al. (2016). Shao and Ünal (2019) show that consumers are willing to pay more for goods with low social and environmental impact in European countries. However, such an empirical evidence is limited to high-income countries, where, according to the analysis presented in this paper, the effects of parenthood and the number of children are null. Taken together, this evidence suggests that green purchasing should be especially promoted in middle- (and perhaps low-) income countries.

The results presented in this paper may also suggest some action to the marketing divisions of the firms producing green goods. There are two main suggestions. The first is that, to increase sales of their green products, they may target young and middle-age fathers specifically. The second is that they may start campaigns that reduce prices for families with (many) children. Besides increasing sales through the reduction of prices, such an action may also better off the image of the firm, whose social responsibility would be strengthened. In addition, such a campaign might be positively welcomed especially in those countries of continental Europe, where fertility rates are low. A combination of public-private policies in this sense would be desirable. A third possibility for the firms is to strengthen the lines of green products dedicated to children and to parents. Increasing the supply may stimulate the demand, with positive externalities through the peer effect in consumption. Of course, such a strategy may lead the firms to over-differentiate their products, generating negative externalities in terms of pollution, as the theoretical literature has already warned. Punzo et al. (2019) suggest that in advanced European countries consumers respond to values and perceived subjective responsibility when choosing whether adopting pro-environment behaviours. It is possible that the same psychological constructs are at work in countries with lower levels of income, but the latter overcome the former because of tighter budget constraints. 
As already mentioned, the main limit of the analysis proposed in the paper is the genericity of the question asked about green purchases. Future analyses are expected to go deeper, using data about how children affect the level of green consumption, allowing for some monetary quantification of the phenomenon. Nevertheless, the results of the present work constitute a positive basis on which planning researches based on more complete datasets.

Funding Open access funding provided by Università degli Studi di Torino within the CRUI-CARE Agreement. No funding was received for this work.

\section{Compliance with ethical standards}

Conflict of interest The author has no any conflict of interest with any of the institutions mentioned in the paper.

Open Access This article is licensed under a Creative Commons Attribution 4.0 International License, which permits use, sharing, adaptation, distribution and reproduction in any medium or format, as long as you give appropriate credit to the original author(s) and the source, provide a link to the Creative Commons licence, and indicate if changes were made. The images or other third party material in this article are included in the article's Creative Commons licence, unless indicated otherwise in a credit line to the material. If material is not included in the article's Creative Commons licence and your intended use is not permitted by statutory regulation or exceeds the permitted use, you will need to obtain permission directly from the copyright holder. To view a copy of this licence, visit http://creativecommons.org/licenses/by/4.0/.

\section{Appendix A: list of countries included in the analyses}

See Tables 7 and 8 
Table 7 List of the countries included in the analyses

\begin{tabular}{ll}
\hline Albania & Malaysia \\
Algeria & Mali \\
Australia & Mexico \\
Bangladesh & Moldova \\
Belarus & Morocco \\
Bosnia-Herzegovina & Nigeria \\
Brazil & Norway \\
Bulgaria & Pakistan \\
Burkina Faso & Philippines \\
Canada & Poland \\
Chile & Romania \\
China & Russia \\
Colombia & Rwanda \\
Cyprus & Saudi Arabia \\
Dominican Republic & Serbia \\
Egypt & Slovakia \\
Ethiopia & Slovenia \\
France & South Africa \\
Georgia & Spain \\
Germany & Sweden \\
Ghana & Switzerland \\
Guatemala & Thailand \\
India & Trinidad and Tobago \\
Indonesia & United Kingdom \\
Iran & United States \\
Italy & Uruguay \\
Jordan & Ukraine \\
Kyrgyzstan & Venezuela \\
Latvia & Vietnam \\
Lithuania & Zambia \\
Macedonia & \\
\hline & \\
\hline
\end{tabular}


Table 8 Countries by cluster

\begin{tabular}{|c|c|c|}
\hline Cluster 1 & Cluster 2 & Cluster 3 \\
\hline Albania & Bangladesh & Australia \\
\hline Argentina & Bosnia-Herzegovina & Canada \\
\hline Brazil & Bukina-Faso & Cyprus \\
\hline Bulgaria & China & France \\
\hline Chile & Dominican Republic & Germany \\
\hline Colombia & Egypt & Italy \\
\hline Kyrgyzstan & Ethiopia & Norway \\
\hline Latvia & Ghana & Saudi Arabia \\
\hline Lithuania & Guatemala & Sweden \\
\hline Malaysia & India & Switzerland \\
\hline Mexico & Indonesia & Trinidad and Tobago \\
\hline Moldova & Jordan & United Kingdom \\
\hline Poland & Mali & United States \\
\hline Romania & Morocco & Venezuela \\
\hline Russia & Nigeria & \\
\hline Slovakia & Pakistan & \\
\hline South Africa & Philippines & \\
\hline Spain & Rwanda & \\
\hline \multirow[t]{4}{*}{ Ukraine } & Tanzania & \\
\hline & Thailand & \\
\hline & Vietnam & \\
\hline & Zambia & \\
\hline
\end{tabular}

\section{Appendix B: methodology}

The data are analysed through well-established econometric techniques (Probit and Heckman selection models are indeed run). The two methods used are probit and Heckman selection models. The first rely on maximum likelihood estimation, which allows to estimate how the probability of observing a given event (represented by the dependent variable of the regression) changes when some other variable (regressor) does. Such a technique is particularly useful when the dependent variable is either dichotomous or discrete and ordered. Green purchasing is represented in this paper by a dummy variable, thus rendering probit estimates particularly adequate.

A problem of selection bias may however arise, as some of the interviewees have children while others do not. Indeed, there might be individual characteristics that explain both the decision of having children and that of purchasing green goods, the data are firstly analysed using a Heckman selection model. This has the advantage of presenting the results for the determinants of green purchasing clean of the effect of the variables affecting the decision of having children. ${ }^{6}$ However, the second step of the Heckman selection model

\footnotetext{
${ }^{6}$ In the first stage of the estimation, the Heckman selection model corrects for the bias that may arise from the fact that parents may not be a random sample of the population. Indeed, being coupled, employed, etc., may depend on unobservable characteristics that are also related to parenthood and therefore influence the probability of having children. In other words, parents and non-parents may differ with respect to unobservable characteristics that are related to other observables. Without any correction for this self-selection into parenthood, estimates based on a sample of only parents may be biased. The second stage of a Heckman
} 
entails ordinary least squares (OLS) estimation. When, as in the case presented in this analysis, the dependent variable is dichotomous, the second step of the Heckman model produces linear probability estimates (LPE), instead of the maximum likelihood estimates (MLE) that a probit or logit model would produce. The main difference between LPE and probit or logit model (Caudill 1988) is that the first methodology may lead to a sum of the probabilities attached to the alternative options, which is larger than one. However, Angrist and Pischke (2009) show that the LPE are less distorted than MLE when the underlying hypotheses on the distribution form of the error terms and of the dependent variable are violated (which occurs the most of the times in the empirical works). For this reason, both the Heckman selection model (HSM) is used to estimate the effect of the number of children on the attitude to purchase green products, and, in addition, the paper presents other estimates, obtained through MLE.

Controlling for country specific fixed effects is very important as Liobikienè et al. (2016) show the presence of differences between countries, even when they are all EU members, i.e. more homogeneous than those used in the present work. Of course, one might focus on one country at a time, or perform separate analyses for each country. However, this procedure may produce results that are valid for a country, but not for others. The point here is that the environmental policies are generally designed at supranational level, as pollution, resource depletion, etc., are world-scale problems and require international responses. One might argue that green consumption is a local issue, as many producers of green goods are local. While this is true, it is also true that multinational companies, which exploit economies of scale, produce large shares of many products (such as cars, food, clothes, paper, etc.), which may be produced so to be green. To convince them to opt for green goods, the possibility of selling them in large markets should exist, in terms of a large-enough number of potential consumers.

Pooling all the countries together in the same regression has the abovementioned advantages. However, such a procedure may hide differences between groups of countries that are homogeneous in terms of levels of income and environmental concern and policies. To account for these possible differences, the countries included in the study are clustered in three groups, according to the relevant information about levels of income and environmental indicators. These variables are those listed before in this section of the paper. However, for the clustering procedure, they cannot be used in their original format, as the units of measures are too different from each other; therefore the different scales may lead to clusters that are more representative of some dimensions (for example GDP or $\mathrm{CO}_{2}$ emissions) not because these are more important, but as their scale artificially increases their relative weight. To solve this problem, a principal component analysis (PCA) ${ }^{7}$ is run before clustering the countries to extract the main factors that explain the observed variance of the data. Four components display an eigenvector larger than one and are thus retained, and used to generate the clusters of countries for the analysis. These clusters are generated through the method of the distance from the centroid, individuated as the mean point of the four components in the four-dimensional hyperspace. Different numbers of clusters were tried, and three were chosen in the end. Such a choice was dictated by the need of preserving a

Footnote 6 (continued)

selection model — which estimates the effects of the variable on interest within the selected subsampledecreases the potential bias, through the correction performed in the first stage.

7 Pearson (1901). The PCA is widely used in the construction of environmental indicators (Zhou and Yoshino 2017). 
sufficiently large number of observations in each cluster for the following empirical analysis. The countries that enter each cluster are listed in Table 8 in "Appendix." It is possible to notice that the first cluster is composed by middle-income countries, with relatively low environmental indicators (high per capita electricity consumption, small extensions of protected areas), and low population density. The second cluster includes middle-income countries with relatively high population density and relatively high environmental indicators (low per capita consumption of electricity, low $\mathrm{CO}_{2}$ emissions, but also small extensions of protected areas). Finally, the third cluster includes high-income countries with high carbon emissions and high electricity consumptions, but large shares of territory in protected areas. Spain and Chile belong to the first cluster in spite of their relative high income, as low population density and high electricity consumption per capita characterise them, which prevail on the level of income.

While the aggregate sample of countries is divided in age clusters to analyse the different effects of children at different parents' ages, the same strategy was not applied to the three aforementioned clusters. The reason behind such a choice is to preserve a sufficiently large number of observations in each cluster for the analysis to be reliable.

\section{References}

Ali, A., Khan, A. A., Ahmed, I., \& Shahzad, W. (2011). Determinants of Pakistani consumers' green purchase behavior: Some insights from a developing country. International Journal of Business and Social Science, 2(3), 217-226.

Angrist, J. D., \& Pischke, J.-S. (2009). Mostly Harmless Econometrics. Princeton: Princeton University Press.

Barber, N., Taylor, C., \& Strick, S. (2009). Wine consumers' environmental knowledge and attitudes: Influence on willingness to purchase. International Journal of Wine Research, 1(1), 59-72.

Blom, N., Kraaykamp, G., \& Verbakel, E. (2017). Couples' division of employment and household chores and relationship satisfaction: A test of the specialization and equity hypotheses. European Sociological Review, 33(2), 195-208.

Capello, R., Caragliu, A., \& Fratesi, U. (2015). Spatial heterogeneity in the costs of the economic crisis in Europe: Are cities sources of regional resilience? Journal of Economic Geography, 15(5), 951-972.

Caudill, S. B. (1988). An advantage of the linear probability model over Probit or Logit. Oxford Bulletin of Economics and Statistics, 50(4), 425-427.

Chan, K. (2000). Market Segmentation of green consumers in Hong Kong. International Journal of Consumer Marketing, 12(2), 7-24.

Chan, R. (2000). Antecedents of green purchases: A survey in China. Journal of Consumer Marketing, 17(4), 338-357.

Chekima, B., Seyed, A. W. S., Wafa, K., Igau, O. A., Chekima, S., \& Sondoh Jr, S. L. (2016). Examining green consumerism motivational drivers: Does premium price and demographics matter to green purchasing? Journal of Cleaner Production, 112, 3436-3450.

Chen, T. B., \& Chai, L. T. (2010). Attitude towards the environment and green products: Consumers' perspectives. Management Science and Engineering, 4(2), 27-39.

Cherian, J., \& Jacob, J. (2012). Green marketing: A study of consumers' attitude towards environment friendly products. Asian Social Science, 8(2), 117-126.

Coad, A., de Haan, P., \& Woersdofer, J. S. (2009). Consumer support for environmental policies: An application to purchases of green cars. Ecological Economics, 68(7), 2078-2086.

Craig, L., \& Baxter, J. (2016). Domestic outsourcing, housework share and subjective time pressure: Gender differences in the correlates of hiring help. Social Indicators Research, 125(1), 271-288.

Croson, R., \& Gneezy, U. (2009). Gender differences in preferences. Journal of Economic Literature, 47(2), 448-474.

de Medeiros, F., Janine, J. L., Ribeiro, D., \& Cortimiglia, M. N. (2016). Influence of Perceived value on purchasing decisions of green products in Brazil. Journal of Cleaner Production, 110, 158-169.

de Medeiros, J. F., \& Ribeiro, J. L. D. (2017). Environmentally sustainable innovation: Expected attributes in the purchase of green products. Journal of Cleaner Production, 142, 240-248. 
Delle Fave, A., \& Massimini, F. (2004). Parenthood and the quality of experience in daily life: A longitudinal study. Social Indicators Research, 67(1), 75-106.

Dholakia, R. R., Pedersen, B., \& Hikmet, N. (1995). Married males and shopping: are they sleeping partners? International Journal of Retail and Distribution Management, 3(23), 27-33.

Diamantopoulos, A., Schlegelmilch, B. B., Sinkovics, R. R., \& Bohlen, G. M. (2003). Can socio-demographics still play a role in profiling green consumers? A review of new evidence and an empirical investigation. Journal of Business Research, 56(6), 465-480.

Fransson, N., \& Gärling, T. (1999). Environmental concern: Conceptual definitions, measurement methods, and research findings. Journal of Environmental Psychology, 19(4), 369-382.

Gan, C., Wee, H. Y., Ozanne, L., \& Kao, T.-H. (2008). Consumers' purchasing behavior towards green products in New Zealand. Innovative Marketing, 4(1), 93-102.

Gilg, A., Barr, S., \& Ford, N. (2005). Green consumption or sustainable lifestyles? Identifying the sustainable consumer. Futures, 37(6), 481-504.

Goh, S. K., \& Balaji, M. S. (2016). Linking green skepticism to green purchase behavior. Journal of Cleaner Production, 131, 629-638.

Halbheer, D., Niggli, S., \& Schmutzler, A. (2006). What does it take to sell environmental policy? An empirical analysis of referendum data. Environmental \& Resource Economics, 33, 441-462.

Hughner, S., Renée, P. M., Prothero, A., Shultz II, C. J., \& Stanton, J. (2007). Who are organic food consumers? A compilation and review of why people purchase organic food. Journal of Consumer Behaviour, 6(1), 1-17.

Jansson, J., Marell, A., \& Nordlund, A. (2010). Green consumer behavior: Determinants of curtailment and eco-innovation adoption. Journal of Consumer Marketing, 27(4), 358-370.

Kaufmann, H. R., Panni, M. F. A. K., \& Orphanidou, Y. (2012). Factors affecting consumers' green purchasing behavior: An integrated conceptual framework. Amfiteatru Economic, 14(31), 50-69.

Kuruvilla, S. J., Joshi, N., \& Shah, N. (2009). Do men and women really shop differently? An exploration of gender differences in mall shopping in India. International Journal of Consumer Sudies, 33(6), $715-723$.

Laroche, M., Bergeron, J., \& Barbaro-Forleo, G. (2001). Targeting consumers who are willing to pay more for environmental friendly products. Journal of Consumer Marketing, 18(6), 503-520.

Liobikienè, G., Mandravickaitè, J., \& Bernatonienè, J. (2016). Theory of planned behavior approach to understand the green purchasing behavior in the EU: A cross-cultural study. Ecological Economics, $125,38-46$.

Liobikienè, G., Mandravickaitè, J., \& Bernatonienė, J. (2017). Environmentally friendly behaviour and green purchase in Austria and Lithuania. Journal of Cleaner Production, 142, 3789-3797.

Mazar, N., \& Zhing, C.-B. (2010). Do green products make us better people? Psychological Science, 21(4), 494-498.

Migheli, M. (2014). Preferences for government interventions in the economy: Does gender matter? International Review of Law and Economics, 39(1), 39-48.

Migheli, M. (2018). Brown parents, green dads: Gender, children and environmental taxes. Journal of Cleaner Production, 180, 183-197.

Mostafa, M. M. (2007). Gender differences in Egyptian consumers' green purchase behaviour: The effects of environmental knowledge, concern and attitude. International Journal of Consumer Studies, 31(3), 220-229.

Nelson, E., Uwasu, M., \& Polasky, S. (2007). Voting on open space: What explains the appearance and support of municipal-level open space conservation referenda in the United States. Ecological Economics, 62, 580-593.

Nittala, R. (2014). Green consumer behavior of the educated segment in India. Journal of International Consumer Marketing, 26(2), 138-152.

Paul, J., \& Rana, J. (2012). Consumer behavior and purchase intention for organic food. Journal of Consumer Marketing, 29(6), 412-422.

Pearson, K. (1901). On lines and planes of closest fit to systems of points in space. The London, Edinburgh, and Dublin Philosophical Magazine and Journal of Science, 2(11), 559-572.

Peattie, K. (2010). Green consumption: Behavior and norms. Annual Review of Environment and Resources, 35, 195-228.

Punzo, G., Panarello, D., Pagliuca, M. M., Castellano, R., \& Aprile, M. C. (2019). Assessing the role of perceived values and felt responsibility on pro-environmental behaviors: A comparison across four EU countries. Environmental Science \& Policy, 101, 311-322.

Rahbar, E., \& Wahid, N. A. (2011). Investigation of green marketing tools' effect on consumers' purchase behavior. Business Strategy Series, 12(2), 73-83. 
Roberts, J. A. (1996). Green consumers in the 1990s: Profile and implications for advertising. Journal of Business Research, 36(3), 217-231.

Rodríguez, C., Miguel, L.-C., \& Oueslati, W. (2016). Air pollution and urban structure linkages: Evidence from European cities. Renewable and Sustainable Energy Reviews, 53, 1-9.

Schlegelmich, B. B., Bohlen, G. M., \& Diamantopoulos, A. (1996). The link between green purchasing decisions and measures of environmental consciousness. European Journal of Marketing, 30(5), 35-55.

Schober, P., \& Scott, J. (2012). Maternal employment and gender role attitudes dissonance among British men and women in the transition to parenthood. Work, Employment and Society, 26(3), 514-530.

Shao, J., \& Ünal, E. (2019). What do consumers value more in green purchasing? Assessing the sustainability practices from demand side of business. Journal of Cleaner Production, 209, 1473-1483.

Shen, J., \& Saijo, T. (2009). Does an energy efficiency label alter consumers' purchasing decisions? A latent class approach based on a stated choice experiment in Shanghai. Journal of Environmental Management, 90(11), 3561-3573.

Shrum, L. J., McCarty, J. A., \& Lowrey, T. M. (1995). Buyer characteristics of the green consumer and their implications for advertising strategy. Journal of Advertising, 24(2), 71-82.

Straughan, R. D., \& Roberts, J. A. (1999). Environmental segmentation alternatives: a look at green consumer behavior in the new millennium. Journal of Consumer Marketing, 16(6), 558-575.

Suki, N. M. (2016). Consumer environmental concern and green product purchase in Malaysia: Structural effects of consumption values. Journal of Cleaner Production, 132, 204-214.

Thalmann, P. (2004). The public acceptance of green taxes: 2 million voters express their opinion. Public Choice, 119, 179-217.

Thompson, L., \& Walker, A. J. (1989). Gender in families: Women and men in marriage, work and parenthood. Journal of Marriage and Family, 51(4), 845-871.

Vazifehdoust, H., Taleghani, M., Esmaeilpour, F., Nazari, K., \& Khadang, M. (2013). Purchasing green to become greener: Factors influence consumers' green purchasing behavior. Management Science Letters, 3(9), 2489-2500.

Voicu, M., Voicu, B., \& Strapcova, K. (2009). Housework and gender inequality in European countries. European Sociological Review, 25(3), 365-377.

Xiao, C., \& McCright, A. M. (2015). Gender differences in environmental concern: Revisiting the institutional trust hypothesis in the USA. Environment and Behavior, 47, 17-37.

Yadav, R., \& Pathak, G. S. (2017). Determinants of consumers' green purchase behavior in a developing nation: Applying and extending the theory of planned behavior. Ecological Economics, 134, 114-122.

Zhao, H.-H., Gao, Q., Yao-ping, Wu., Wang, Y., \& Zhu, X.-D. (2014). What affects green consumer behavior in China? A case study from Qingdao. Journal of Cleaner Production, 63, 143-151.

Zhou, T., \& Yoshino, K. (2017). Environmental vulnerability evaluation using a spatial principal components approach in the Daxing'anling region, China. Ecological Indicators, 78, 405-415.

Zhu, Q., Li, Y., Geng, Y., \& Qi, Yu. (2013). Green food consumption intentions, behaviors and influencing factors among Chinese consumers. Food Quality and Preference, 28(1), 279-286.

Ziegelmeyer, F., \& Ziegelmeyer, M. (2016). Parenting is risky business: Parental risk attitudes in small stakes decisions on behalf of their children. Review of Economics of the Household, 14, 599-623.

Publisher's Note Springer Nature remains neutral with regard to jurisdictional claims in published maps and institutional affiliations. 